\title{
O Nordeste, as imagens e o ensino: o real e o imaginário na iconografia da seca
}

\begin{abstract}
Resumo
Em parceria montada pela urgência que se impõe pelo entendimento do Ensino como uma área de saber comungante, este artigo compendia um empreendimento associativo com pesquisadores da Educação e da Iconografia que percebem a Imagem como um tipo de modalidade de linguagem interativa, fomentadora de conhecimentos e que se pontifica também no cotidiano e nas espacialidades da escola. Amalgamado por teóricos que conceituam e problematizam a Imagem para além de mera ilustração, o Nordeste brasileiro, outra vez, perfilha-se em novos suspiros e em um sinergismo para se fazer problematizar por olhares de historiadores, literatos, romancistas e atores outsiders. Em uma perspectiva interdisciplinar, analisa-se então a incrustação das imagens e sua aplicabilidade capaz de instrumentalizar os estereótipos e a bipolaridade existente entre o real e o imaginário acerca do Nordeste.
\end{abstract}

Palavras-chave: Ensino. Nordeste, Estereótipo. Real e Imaginário.
Paulo Augusto Tamanini

Universidade Federal Rural do SemiÁrido - UFERSA - Mossoró/RN Brasil

paulo@tamanini.com.br

\section{Enock Douglas Roberto da Silva}

Secretaria de Educação do Estado do Ceará - Fortaleza/CE - Brasil enockdouglas@hotmail.com

\section{Para citar este artigo:}

TAMANINI, Paulo Augusto; SILVA Enock Douglas Roberto da. O Nordeste, as imagens e o ensino: o real e o imaginário na iconografia da seca. Revista Linhas. Florianópolis, v. 20, n. 43, p. 317-337, maio/ago. 2019. 


\title{
The Northeast, the images and the teaching: the real and the imaginary in the iconography of the drought
}

\begin{abstract}
In a partnership set up by the urgency that is imposed by the understanding of Teaching as an area of communal knowledge, this article compends an associative enterprise with researchers of Education and Iconography that perceive the Image as a kind of interactive language modality, fomenting of knowledge and that is also pontificates in the daily life and in the spaceships of the School. Amalgamated by theoreticians who conceptualize and problematize the Image, beyond mere illustration, the Brazilian Northeast, once again, has new sighs and a synergism to be made problematic by the looks of historians, writers, novelists and outsiders. In an interdisciplinary perspective, the image encrustation is analyzed and its applicability capable of instrumentalizing the stereotypes and the bipolarity existing between the real and the imaginary about the Northeast.
\end{abstract}

Keywords: Teaching. Northeast. Stereotype. Real and Imaginary. 


\section{Introdução}

A espetacularização da imagem como estereótipo torna-se o mote investigativo deste artigo, oferecendo alguns elementos para um pensar teórico acerca das práxis em que a visualidade encontra um salvo-conduto explicativo. Se por vezes, as ilustrações têm a função de realçar o escriturístico, podem, outrossim, esconder intenções em que a História não pode se arvorar omissa. Até porque, nem sempre a imagem serve somente para corroborar a descrição verbal de um fato. Ela em si é também uma narrativa. A plasticidade, a forma, as cores que formatam uma imagem são elementos de uma representação plenipotenciária de um real ou da ideia de um real longe de qualquer distopia.

O interesse neste artigo é ver como o Nordeste brasileiro é representado pelas imagens; que aspectos da cultura nordestina são enfatizados ou abordados nos filmes, livros, didáticos, literatura. Como noção de cultura, usa-se aquela dada por Jean Pierre Warnier, que a compreende como a bússola de uma sociedade, geograficamente localizada, em torno da qual se agregam tanto as crenças, as leis, os costumes, quanto os fazeres de um grupo, e que irão guiar as suas escolhas, seja no plano das ações, seja no das representações. Ou, nas palavras do autor, "cultura é uma totalidade complexa feita de normas, de hábitos, de repertórios de ação e de representação, adquirida pelo homem enquanto membro de uma sociedade" (WARNIER, 2000, p. 23). É, portanto, no âmbito dessa noção de cultura que são formadas as imagens mentais acerca do Nordeste. E, segundo Sandra Pesavento, essas ideias mentais são as representações que aludem à uma presentificação da ausência. Portanto, “é uma representação que não é uma cópia do real, sua imagem perfeita, espécie de reflexo, mas uma construção feita a partir dele" (PESAVENTO, 2003, p. 40). Logo, as representações são discursos traduzidos ora por palavras, ora por imagens, ora por símbolos que necessitam de métodos e aportes teóricos para ser lidas, percebidas e arguidas.

As novas metodologias e novos aportes teóricos transformaram a História Cultural em exímia exegeta do elemento imagético presente nos livros didáticos, impingindo nele a crítica quando estes negligenciam a autonomia das figuras no texto. Compreende-se que entre imagem e texto não pode haver manobras literárias, acordos velados que cumpliciam as intenções ou que estejam à mercê de comprometimentos ideológicos e 
políticos. A historiografia, agora também ocupada e atenta às finalidades do uso das imagens, não enxerga mais as ilustrações como instrumentos de deleite, mas pelo contrário, faz a partir delas algumas intervenções, retirando das sombras do deslumbre a objetividade da qual a História diz-se depositária.

Na maioria das vezes, os livros didáticos representam o Nordeste de modo estereotipado, parcial e incompleto. Assim, movidos por interesses de ideologias usurpadoras do real, a presença das imagens em certos casos faz confundir e põe sob suspeita os direcionamentos editoriais e a licitude da escrita verbal. Quando não se encontra nexo entre a narrativa e a textualidade das imagens, verifica-se um distanciamento, um conflito e lacunas imperdoáveis, porque alimentadoras de estereótipos nocivos e preconceituosos. Assim, a porosidade e a frágil coesão entre o corpo imagético veiculado e espetacularizado nos livros didáticos evidenciam a existência de um fosso incapaz de sedar o modo díspar de se pensar a ideia de um real e a maneira de estereotipá-lo. Essa dessemelhança sinaliza uma vertigem entre o lido e o percebido, entre o redigido e o visto, entre o escutado e o assimilado, enfim, entre a intenção e a reação. Tais assimetrias são objetos de burburinhos, discordâncias, litígios exegéticos, ora mitigados, ora exacerbados: mas são também uma oportunidade para se perguntar como os historiadores, os pesquisadores, os docentes e os discentes analisam as linguagens, o texto, o símbolo. Não, certamente, para se iludirem de contornar as premissas da divisão com uma artimanha filológica, mas para se perguntarem qual é o nexo existente entre a imagem e o texto.

\section{A escrita da História: períodos e demandas}

A escrita e o ensino de História sempre estiveram determinados pelas tendências historiográficas a que seus autores estavam filiados. Logo, a escrita da história atende a um contexto político no qual os autores estão inseridos (CERTEAU, 2008). Até porque, o conhecimento não pode ser desvinculado do seu contexto histórico e do seu lugar de fala. Para Marc Bloch, a história é entendida como construção do seu tempo (BLOCH, 2001). 
Pensar o ensino de História é situar o contexto social em que a disciplina de História é exercida. Ela, como disciplina, surgiu na França do século XIX, imbricada aos movimentos de laicização da sociedade e de constituição das nações modernas (NADAI, 1993). A História nesse período é marcada por uma a visão positivista ${ }^{1}$. A partir do século XX, conforme Bloch (2001), a História passou por uma renovação teórica e metodológica. Iniciou-se uma nova perspectiva na sua compreensão que teve como berço a Escola dos Annales ${ }^{2}$. Nas décadas de 1950 e 1960, os estudos de Fernand Braudel, da $2^{\circ}$ geração dos Annales, e os estudos da Nova História cultural, em 1980, possibilitaram a discussão de uma história fragmentada com novos temas e aportes conceituais. Toda essa revolução no campo historiográfico possibilitou outros olhares, novos objetos e novos métodos, o que promoveu uma vasta ampliação do conceito de fontes. Assim, documentos escritos, processos, imagens, fotografias, objetos materiais, depoimentos orais e testemunhos passaram a ser fontes históricas.

As novas propostas estabelecidas pelos Parâmetros Curriculares Nacionais (PCN) apresentam possibilidades de trabalhar os conteúdos de História envolvendo imagens. No entanto, o professor deve fazer uma articulação entre os métodos do historiador e os métodos pedagógicos para fazer as análises de imagens. No que se refere à organização dos conteúdos de História, de acordo com Bezerra, "esses devem ultrapassar as barreiras da linearidade e sequencialidade" (BEZERRA, 2010, p. 40).

De acordo com Bezerra (2010), os Parâmetros Curriculares Nacionais (PCN) propõem uma proposta diferenciada com eixos temáticos, esperando uma maior liberdade e criatividade do professor. Nesse momento, surgem questões de como o Nordeste foi retratado a partir de imagens nos livros didáticos de História, assim como na literatura e na mídia atual.

No presente trabalho, considera-se como metodologia uma análise teórica e documental, com estudos clássicos de NADAI (1993); BITTENCOURT (2015); BEZERRA

\footnotetext{
${ }^{1}$ Priorizava o interesse em uma história política e social que enaltecia as figuras dos grandes heróis, reis, imperadores. Estabelecia uma sequência linear, factual baseada em importantes fatos e acontecimentos.

${ }^{2}$ A Escola dos Annales ou revista dos Annales surgiu na França em 1929, e era composta por historiadores como Lucian Febvre e Marc Bloch. Nessa nova concepção, se distanciaram da História política e deram espaço ao econômico e social.
} 
(2010); ALBURQUERQUE Jr.(2001); PAIVA (2006) que ajudam a discutir e problematizar o ensino de História no Brasil e a construção de estereótipos por meio de imagens.

\section{Imagens nos livros didáticos}

Cabe salientar que no livro didático tem-se uma grande quantidade de imagens que podem ser usadas nas aulas de História. Porém, a amplitude das imagens fixas, fotografias, charges devem ser bem problematizadas pelo professor. Sabemos da importância e da dificuldade dos professores fazerem uma análise crítica das imagens, pois estas estão sujeitas a contínuas interpretações.

Conforme Paiva, "a iconografia é, certamente, uma fonte histórica das mais ricas, que traz embutida as escolhas do produtor e todo o contexto no qual foi concebida, idealizada, forjada ou inventada" (PAIVA, 2006, p. 17).

Quanto a uso de imagens no ensino de História é importante perceber que sua leitura se faz através tanto de indagações como também interpretação. Portanto, reconhece-se que as imagens são representações estáticas, mas se modificam muitas vezes de acordo com as exigências fomentadas pelo Programa Nacional do Livro Didático (PNLD). A complexidade da obra didática se relaciona com várias perspectivas, com questões de interesses no que tange ao domínio de ordem econômica, política, ideológica, cultural e pedagógica na sua elaboração. Diante disso, os livros didáticos são frutos de um período histórico, de uma cultura que percebe a si e ao outro, a partir dos seus valores culturais, da sua identidade, que se organiza através dos currículos.

Nesse cenário, "o livro didático é uma mercadoria, um produto do mundo da edição que obedece à evolução de técnicas e de fabricação e comercialização pertencentes à lógica do mercado" (BITTENCOURT, 2015, p. 71).

As imagens são analisadas de acordo com o contexto da época e com o objetivo do autor, destacando alguns aspectos e ocultando outros. Sendo assim, a abordagem didática com o uso de imagens possibilita perceber que os discursos de representação não são neutros, mas cabe às produções didáticas, ao apresentarem tais imagens, situarem-nas em reflexões que possibilitem a percepção crítica sobre a forma com que os sujeitos históricos ou grupos culturais são representados. 
Conforme Paiva (2006), na imagem existem lacunas, silêncios e códigos que precisam ser decifrados, identificados e compreendidos. Segundo o autor, devemos ter cuidado para não cair numa armadilha historiográfica, que é transformar as imagens em ilustrações ou em figurinhas de texto. Com isso, percebe-se que:

\begin{abstract}
A imagem não é retrato de uma verdade, nem representação fiel dos eventos ou de objetos históricos. A imagem ao ser lida pelo historiador, pelo especialista e pelo leigo é reconstruída a cada época, elas podem despertar maior ou menor interesses em cada momento histórico, de acordo com a apropriação que faz delas. (PAIVA, 2006, p. 20)
\end{abstract}

Na leitura de imagens há sempre "a arbitrariedade, a parcialidade e as escolhas do observador e do historiador, o que garante sempre, olhares e versões diferentes sobre o mesmo objeto" (PAIVA, 2006, p. 55).

Cidades, regiões, povos, todos têm intrínseco em suas características, vidas, histórias, hábitos e costumes que se dizem próprios. Entende-se portanto, que nenhuma cultura é superior a outra. A presente pesquisa objetiva discutir acerca das representações históricas que contribuíram e contribuem na constituição da imagem do nordestino sertanejo atrelado a estereótipos e preconceitos. Buscando entender como e a partir de quando alguns meios como mídia, literatura e artes passaram a representar o Nordeste como uma região extremamente pobre, seca e miserável, inferindo de certa forma a uma região e cultura inferior. Apresenta, ao mesmo tempo, uma dualidade entre o que é visto de fora, sem conhecimento, e o que realmente o Nordeste apresenta em sua estrutura social e cultural. Não renegando, claro, nossos problemas sociais, exclusões.

Em nenhum momento a pesquisa busca demonstrar o Nordeste como uma região sem problemas, ou perfeita, mas, sim, refletir e analisar sobre fatos e imagens errôneas, distorcidas e preconceituosas. No que se refere às imagens da cultura nordestina, devemos fazer uma viagem ao passado dessa gente, gente do sertão, relembrando grandes secas que afligiram essa terra; isso se faz necessário para entender a gênese da imagem do Nordeste de mazelas, onde realmente, a morte pela fome era presente, mas 
também vamos relembrar saudosos artistas que se fizeram em meio a tais mazelas, como o Luiz Gonzaga.

Para Albuquerque Jr., a região Nordeste que emerge na "paisagem imaginária" do país nas primeiras décadas do século XX (colocando-se no lugar da antiga divisão regional Norte e Sul) foi fundada na saudade e na tradição. O Nordeste, não mais sob a ótica naturalista-geográfica, foi, como dito acima, uma “elaboração”, uma “invenção”:

O Nordeste não é um fato inerte na natureza. Não está dado desde sempre. Os recortes geográficos, as regiões são fatos humanos, são pedaços de história, magma de enfrentamentos que se cristalizaram, são ilusórios ancoradouros da lava da luta social que um dia veio à tona e escorreu sobre este território. O Nordeste é uma espacialidade fundada historicamente, originada por uma tradição de pensamento, uma imagística e textos que Ihe deram realidade e presença. (ALBUQUERQUE, 2001, p. 23)

A apresentação monológica de um só discurso de representação para a região Nordeste, discurso esse que mantém velhas relações históricas de poder (Centro-Sul versus Norte/Nordeste) envolve procedimentos de exclusão, silenciando outros modos de dizer/mostrar a região, e apresenta um só sentido como natural e real.

Primeiramente, abordamos algumas questões relacionadas aos conceitos de representações, e iconografias, para em seguida apresentarmos conceitos sobre região e identidade regional, através de uma perspectiva discursiva: tomamos como premissa que a identidade regional é fruto de uma construção discursiva mais do que uma verdade essencial. Em seguida, apresentamos um esboço de análise dessa construção discursiva em imagens de livros didáticos, das mídias sociais, literatura e artes, demonstrando em exemplos como se constituíram essas representações em tais recursos.

Recorremos a documentos e outros recursos aos quais tivemos acesso sem delimitação de tempo, então, apresentaremos imagens e exemplos que vão desde o período imperial até o final do século XX, o que resulta em um texto rico de informações e em ilustrações claras sobre os preconceitos atribuídos à região Nordeste. 


\section{Dispositivos discursivos na construção de preconceitos, estereótipos e imaginário}

O estudo das realidades que formam o cotidiano tem se realizado por diferentes vieses, e evidenciam-se os interesses de pesquisadores sobre questões do dia-a-dia e seus significados, e as representações sociais que vão se construindo por meio de hábitos, rituais, nas ruas, na igreja, nas novelas, revistas, jornais, internet, carregam um sentido social e político dessas representações (CHIZZOTI, 1992). A construção das identidades no Brasil carrega uma característica histórica de não aceitação das diversidades de vozes e culturas, a dificuldade de reconhecer o outro em si mesmo. Dessa maneira, propaga-se com muita frequência uma imagem de superioridade de uma região sobre a outra. Essas ideias foram e ainda são reproduzidas por meio de mecanismos como a literatura, a música, os livros didáticos, a televisão e, atualmente, a internet e as redes sociais. Isso nos faz refletir sobre a identidade do povo brasileiro; quem somos? Como nos constituímos? Brasileiro é assim mesmo?

$\mathrm{Na}$ ilustração a seguir, o então presidente da EMBRATUR, durante uma entrevista à revista Agropecuária Tropical, sugere que em plena década de 1980 do século XX se enalteça o turismo da seca, onde a principal atração seria ver os nordestinos morrendo de fome e sede. Uma notável demonstração de total desconhecimento, vinda de um jovem empresário de São Paulo, impulsionado pela imagem distorcida da região e de seu povo, além de uma proposta desumana e desrespeitosa. Vejamos a imagem que propõe investir no turismo das mazelas da seca, mostrando para estrangeiros e pessoas de outras regiões do país o sofrimento no Nordeste.

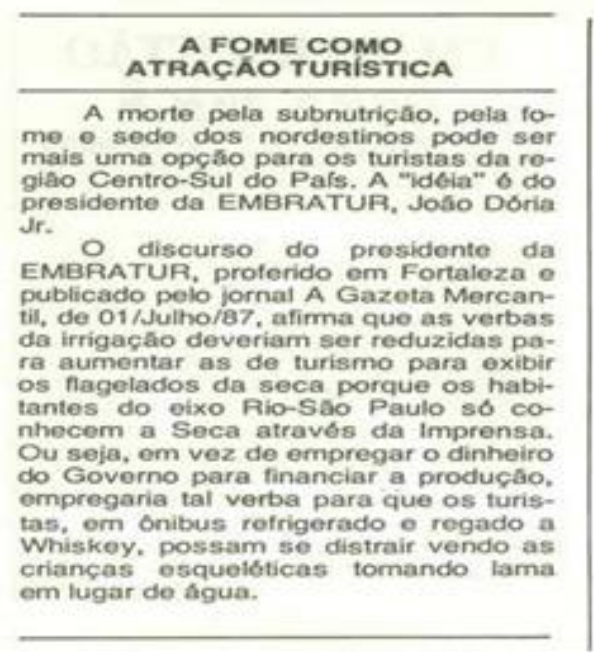

Figura 1: Revista Agropecuária Tropical. Edição set./out. de $1987,58^{\text {a }}$ ed. p. 23. 
Essa declaração do presidente da EMBRATUR, em 1987, demonstra o imaginário que algumas pessoas de outras regiões do Brasil ainda alimentavam, carregada de estereótipos e que se propagava no cotidiano, no dia-a-dia. Em relação à construção da imagem do cotidiano, segundo Certeau,

O cotidiano é aquilo que nos é dado cada dia (ou que nos cabe em partilha), nos pressiona dia após dia, nos oprime, pois existe uma opressão no presente. [...] O cotidiano é aquilo que nos prende intimamente, a partir do interior. [...] É uma história a caminho de nós mesmos, quase em retirada, às vezes velada. [...] Talvez não seja inútil sublinhar a importância do domínio desta história "irracional". (CERTEAU, 1996, p. 31)

Referenciando-nos no pensamento de Certeau, façamos a seguinte reflexão: o imaginário de um Nordeste que é publicizado, muitas vezes por quem nunca esteve na região, é de um lugar de calamidade pública, de fome e miséria, de pessoas com menos instrução. Estereótipo esse reforçado por discursos como o citado acima, e divulgado nas mídias, jornais, livros e até mesmo em livros didáticos produzidos fora da região, muitas vezes por profissionais que desconhecem a realidade local. A imagem tem uma influência muito forte na construção do pensamento, dependendo da sua utilização pode ser uma fonte de construção ou desconstrução de preconceitos.

Para poder apreciar "a diferença ou a semelhança entre a produção da imagem e a produção secundária que se esconde nos processos de sua utilização", Certeau propõe como baliza teórica:

A construção de frases próprias com um vocabulário e uma sintaxe recebidos, supondo que, pelas maneiras de usar essa produção, pelas invenções cotidianas, pelas maneiras de fazer, ocorre com os usuários, a exemplo dos povos indígenas, uma "bricolagem" com e na economia cultural dominante, pela possibilidade de descobrir inúmeras metamorfoses da lei, segundo seus interesses próprios e suas próprias. (CERTEAU, 1994, p. 40)

Nessa perspectiva, a legitimidade da "autoridade", isto é, a expressão daquilo que é "aceito" como "crível” se constrói pelas representações que vão se articulando em 
torno dela e que se traduzem por uma "constelação de referências", fontes, uma história, uma iconografia, em suma, por uma articulação de "autoridades". Ou seja, a toda vontade construtiva são necessários sinais de reconhecimento e acordos feitos acerca das condições de possibilidade, para que seja aberto um espaço no qual se desenvolva (CERTEAU, 1995). São as representações aceitas que, segundo ele, inauguram e, ao mesmo tempo, exprimem essa nova credibilidade.

O escritor potiguar Paulo de Brito Guerra, em sua obra "A Civilização da Seca: O Nordeste é uma história mal contada", de 1981, já apresentava essa construção mal contada sobre o Nordeste, que devido às suas grandes secas e aos flagelos da fome que culminaram ao longo de centenas de anos com a morte de inúmeros sertanejos, impregnou-se essa imagem estereotipada de uma região maldita. O autor em questão trabalhou mais de quarenta anos no $\mathrm{DNOCS}^{3}$, e teve a oportunidade de publicar dezenas de relatórios e trabalhos técnicos sobre assuntos ligados à agronomia nordestina, além de narrativas sobre as secas e costumes sertanejos.

Segundo o autor, o Nordeste de hoje, em muito avançou e se desenvolveu, saindo definitivamente do mapa da fome e da sede, mas para o restante do país, essa região ainda é a mesma de séculos atrás (GUERRA, 1981).

As grandes secas enfrentadas pelo Nordeste deram origem às ações governamentais que culminaram com políticas públicas de convivência com o fenômeno, de construção de açudes, barragens e canais. Atualmente, os agricultores nordestinos são exemplos de agricultura familiar, e o desenvolvendo industrial e tecnológico está em pleno vapor. Guerra afirma que já no início do século XX não existiam mais vítimas das secas:

Nas calamidades seguintes, a partir de 1942, não mais tem havido vítimas da seca, salvo casos isolados. Existia água saudável em grandes reservatórios, onde corriam as maiores aglomerações. Havia bastante peixe, produtos alimentares e forrageiras, que minoravam o sofrimento da gente e do gado, e mais que tudo, a assistência do Governo Federal que passou a ser pronta e eficiente. (GUERRA, 1981, p. 35)

\footnotetext{
${ }^{3}$ Departamento Nacional de Obras de Combate às Secas.
} 
No passado, o vento da seca cheirava à morte. Em 1877, o Nordeste foi desfalcado de quinhentas mil vidas. Segundo narrativa de Aires do Casal, citada por Eloi de Souza (GUERRA, 1981), essa imagem do sertão que cheira à morte ainda é a imagem que alimenta o imaginário de muitas pessoas em outras regiões do país, gerando preconceitos e discriminações até os dias atuais, caracterizando tal discriminação como crime de xenofobia.

A xenofobia ${ }^{4}$ é um medo incontrolável do desconhecido. Ela pode ser caracterizada como um preconceito ou como um transtorno psiquiátrico, depende muito do contexto em que o termo estiver sendo utilizado. No caso do preconceito aos nordestinos, é uma forma, além de preconceito, também de racismo. Não é tão difícil encontrar brasileiros que entendam que os habitantes do Nordeste são uma sub-raça ou, em última análise, um povo miserável sob todos os aspectos, inclusive desinformado.

Dividir o país em duas cores, duas pátrias tem levado muitos nordestinos a sofrerem na pele todo tipo de discriminação em qualquer estado que more, o que é uma lástima. A generalização que a nossa mídia faz quando o assunto é esse contribui para o agravamento da questão, estimulando de sobremaneira o ódio ao diferente. No Brasil, existem leis que tratam sobre o crime de xenofobia, por exemplo, vejamos as que se seguem: A Lei $n^{\circ} 7.716$, de 05 de janeiro de 1989 , em seu artigo $1^{\circ}$ (com a redação determinada pela Lei ${ }^{\circ}$ 9.459, de 13 de março de 1997), diz que

Serão punidos, na forma desta Lei, os crimes resultantes de discriminação ou preconceito de raça, cor, etnia, religião ou procedência nacional. Portanto, claramente, os delitos tipificados por esta lei englobam a conduta de segregar, que vem a ser delito inafiançável e imprescritível. (BRASIL, 1988)

O mais curioso (e triste) de toda esta realidade: ao contrário de países envolvidos em conflitos ou guerras civis, o Brasil não tem divisão de etnias ou tribos, sendo o preconceito movido apenas por questões geográficas. Talvez por esse motivo os embriões de movimentos separatistas sulistas nunca tenham ganhado mais do que algumas páginas na internet e manifestações isoladas.

\footnotetext{
${ }^{4}$ Fonte: <http://brasilescola.uol.com.br/doencas/xenofobia.htm>.
} 


\section{O Nordeste entre temas e imagens: análises e reflexões}

O historiador Durval Muniz Albuquerque Jr. inicia o seu livro A Invenção do Nordeste e outras artes, convidando-nos a olhar o Nordeste na mídia: novelas, documentários, reportagens jornalísticas e, principalmente, programas de humor. O que geralmente aparece em cena é um lugar bem distante (de quem?), com pessoas engraçadas, que falam errado, se vestem com roupas emendadas, usam maquiagem exagerada, dão tiro e peixeiradas para todo lado. O que se encontra de comum em todas essas imagens pitorescas e risíveis é um discurso concreto que produze incômodo nos moradores da região e que pode gerar, ao mesmo tempo, uma intrigante aceitação do lugar de marginal frente a uma cruel estratégia de estereotipização.

Afirmar que as novelas da televisão alimentam estereótipos contra nordestinos não é novidade. É um lugar comum. Há décadas, o Brasil inteiro está habituado a assistir nas novelas personagens "nordestinos" de sotaques e trejeitos carregados, meio cômicos e bastante estridentes, fervorosamente católicos, seres rústicos e brutos. Quase sempre encenam papéis de figurantes e secundários, de mera composição do cenário ou do roteiro. A função principal desses papéis nordestinizados consiste na maior parte das vezes em amenizar o drama principal por meio do riso, da troça, do deboche e do escárnio que tais personagens por suas vicissitudes suscitam.

Os estereótipos formados historicamente ganham visibilidade, dirigindo a imagem do nordestino em todo o país, inclusive na mídia, no cinema, nas músicas e na literatura. O nordestino tende a ser colocado no lugar de vítima da seca e do destino.

No capítulo intitulado Norte versus Sul, do livro a Invenção do Nordeste, Durval Muniz afirma que o sul teria sido o lugar do Brasil determinado naturalmente como uma “Europa” no Brasil, e o Nordeste como uma região rural, uma representação do atraso, da pobreza e da fome, enquanto o sul foi determinado no imaginário popular como a região do progresso (ALBURQUERQUE Jr., 2001).

Continuamos esta pesquisa partindo para um exemplo literário. Entre tantos possíveis, optamos por analisar em síntese a obra de Euclides da Cunha, Os Sertões, publicada em 1902. Nessa obra, podemos inferir argumentações para constituição de ambos os discursos, tanto de uma imagem estereotipada negativa, em que se inferioriza 
o Nordeste, quanto um discurso/imagem estereotipado positivo, em que se enaltece essa região e seu povo.

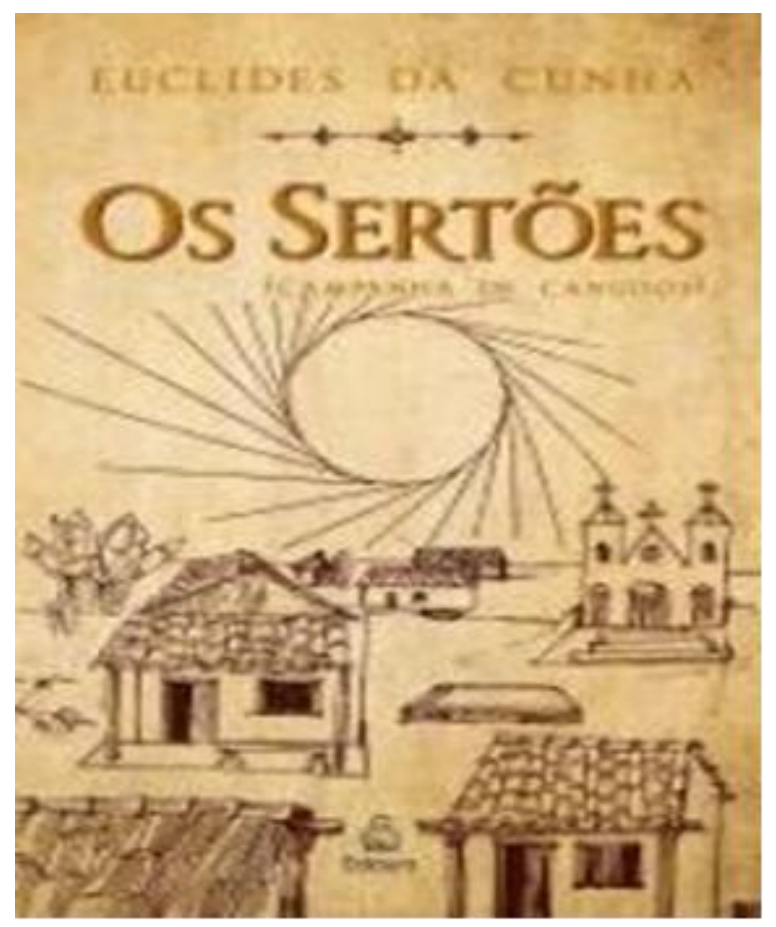

Figura 2. Capa da $1^{\text {a }}$ edição do livro Os Sertões, de Euclides da Cunha. Reprodução. Acervo do autor.

Apesar de suas fortes convicções naturalistas, próprias de uma geração de intelectuais influenciados pelas teorias evolucionistas, deterministas e racistas, Euclides da Cunha se depara com a vida no sertão e, a partir do que assiste durante a guerra de Canudos, é tomado por profundos conflitos epistemológicos visivelmente presentes na sua obra. As imagens que constrói daquele lugar e do homem que o habita são totalmente ambíguas e por vezes contraditórias. Assim, a paisagem desoladora e desértica é a mesma paradisíaca, uma terra que vai da extrema aridez à exuberância extrema (CUNHA, 1973, p. 231), e o seu habitante, o sertanejo, apesar de ser o homem permanentemente fatigado, cambaleante e sem prumo, de um só assalto pode se transformar em um titã acobreado e potente ágil e forte. Enfim, entre os saberes de sua época e a vontade de exaltar a memória dos canudenses, Euclides acaba por levantar uma grande questão para o Brasil: quem será esse povo desconhecido? Vencido ou vencedor? 
Da literatura, partimos para uma análise artística de representação do Nordeste, a pintura, por meio da obra Os Retirantes, de Cândido Portinari, produzida em 1944. Na obra, Portinari expõe o sofrimento dos migrantes, representados por figuras macérrimas e com expressões que transmitem sentimentos como a fome e a miséria.

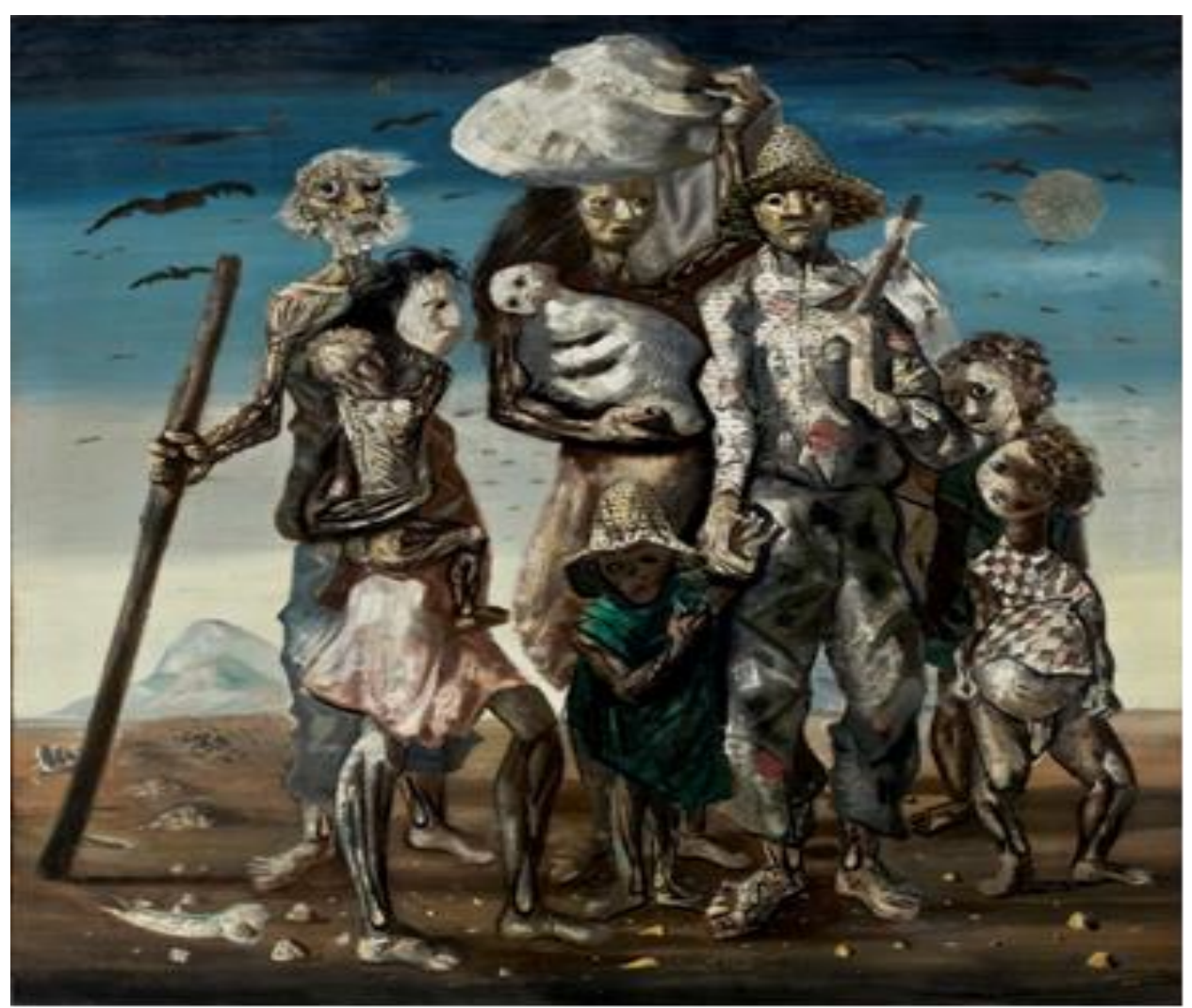

Figura 3. Os Retirantes, de Cândido Portinari, 1944. Reprodução. Acervo do autor.

Na tela é possível identificar nove personagens, todos apresentados de maneira cadavérica, sendo dois homens adultos, duas mulheres adultas e cinco crianças, das quais apenas uma tem o sexo identificado. A obra apresenta um embate entre o sagrado e o profano, sendo o primeiro representado pela família e o segundo pela situação precária e a morte iminente, que se mostra nesse cenário de sofrimento. É possível perceber também a representação do ciclo da vida, que se inicia com a criança na cena e se encerra na figura cadavérica do personagem mais idoso da composição. O contexto histórico da obra é 1944, período em que a imagem estereotipada do Nordeste enquanto região da fome e da morte ainda estava muito relacionada às secas do século anterior. 


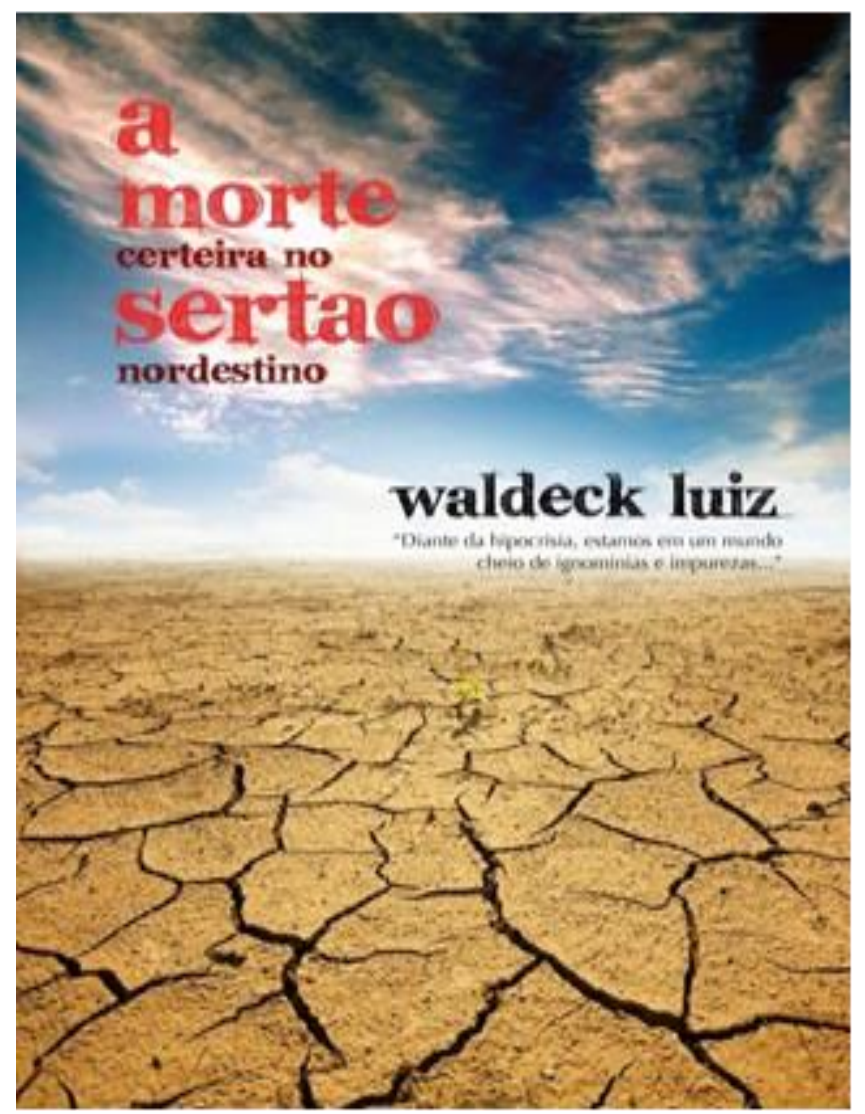

Figura 3: Capa do livro A morte certeira no sertão nordestino, de Waldeck Luiz (2003). Reprodução. Acervo do autor.

No livro A morte certeira no sertão nordestino, Waldeck Luiz (2003) aborda de forma estereotipada que a seca no Nordeste é causadora de mortes, o que na atualidade não ocorre mais, principalmente em virtude de programas de convivência com a seca, do êxodo rural e de programas sociais do Governo Federal. Livros didáticos de História ainda apresentam fortes representações de estereótipos sobre o Nordeste, com imagens que causam choque logo em suas capas, mostrando mortes, o chão seco, animais em estado deplorável, etc.

A próxima imagem refere-se à capa do livro de Hélio Ramos (1987), intitulado Nordeste, nação espoliada. Nele, o autor apresenta o Nordeste como região em grande caos social, como fome e morte generalizadas. 


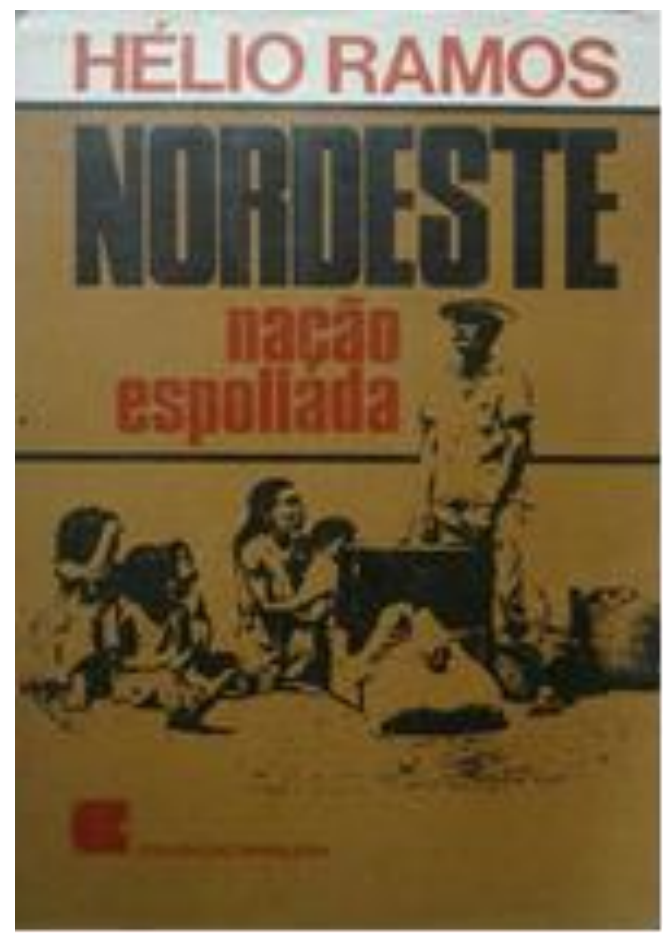

Figura 4: Capa do Livro Nordeste, nação espoliada. Reprodução. Fonte: Acervo do autor.

No dicionário de Aurélio Buarque de Holanda (2012) de Língua Portuguesa, a palavra “espoliado" significa: privado de algo mediante violência ou outro processo ilegítimo. Nesse sentido, o título da obra de Hélio Ramos (1987) infere que o Nordeste é uma região que foi privada de algo, e ao lermos, entendemos que essa privação está relacionada à histórica exclusão da região em relação a apoio governamental e social, mas a violência do casamento entre imagem e texto apresentados na capa do livro, impressiona o leitor leigo, que não conhece o Nordeste, associando a representação de generalização da pobreza e da desgraça.

A região Nordeste é categorizada pelos fatores naturais, sociais, econômicos e culturais, no entanto, por meio de imagens e discursos, esta muitas vezes é estereotipada e generalizada em aspectos específicos. O sertão como percebemos ao longo da pesquisa, é divulgado como uma totalidade na região, mas o Nordeste não é apenas o sertão, assim como não é apenas litoral. O Nordeste é dinâmico, e contempla diferentes realidades, assim como as outras regiões do Brasil que historicamente agregam riqueza, pobreza, desigualdade e má distribuição de renda. 


\section{Considerações finais}

Ao contrário das sedutoras imagens veiculadas em relação à paisagem dos trópicos, a brasilidade expressa na literatura, em filmes, novelas e na música representa aspectos da história, da cultura e da geografia do país, calcados basicamente na região Nordeste como lugar de contundente problemática social, mas a região não é só isso. 0 Nordeste é mais do que dizem dele. É mais do que a mídia, as redes sociais, os filmes e as novelas publicizam sobre ele. E, por conseguinte, é bem mais do que os livros didáticos ensinam. Fora das zonas de conforto construídas pelas convenções, o Nordeste, configurado em seus grupos identitários e linguagens, com suas sociabilidades e pulsantes heranças culturais, sobrevive e se expande à mercê do que dele se combinou pensar. Portadora de sua identidade, a região é também palco da brasilidade onde se mistura e se confabula o humano, tecido pelas riquezas das relações, associações, hibridismos e acordos. O caldo personificador do rosto brasileiro esculpido pelas aragens do semiárido faz dessa região algo provocador de curiosidades, porque desconhecido em sua inteireza.

Este artigo buscou constatar como a mídia, a literatura e principalmente os livros didáticos trazem as representações do Nordeste, por meio de imagens, recortes, ilustrações, filmes, novelas. Materiais de densa carga simbólica, as imagens assim convencionadas sobre o Nordeste denunciam uma presença negativada de aspectos sociais, tais como a miséria, a seca e a pobreza, como suas únicas marcas de identificação. Facilmente levados a cair nas mensurações e julgamentos, os alunos eram, portanto, alimentados por mecanismos de funcionamento de ideologias que ora, validavam alguns conhecimentos e práxis culturais, ora levavam ao detrimento dos considerados folclóricos, senso comum e desorganizados.

A constante publicização e o fabrico de convenções equivocadas e direcionadas levaram então, a se tomar as representações como algo indiscutível, e a formularem uma ideia de que o Nordeste é somente o que está ilustrado nos livros didáticos. Daí porque é premente discutir, sob a ótica da História, acerca das representações imagéticas. Descobertas em um atrelamento de figuras ideológicas, as imagens podem até mesmo arregimentar, forçar e legitimar estereótipos e preconceitos. 
Buscou-se de forma sucinta alguns exemplos de constituições da imagem do Nordeste na literatura, televisão, artes, e que auxiliaram de certa forma, com a construção de estereótipos sobre essa região. Entendemos que se faz necessário um aprofundamento teórico-metodológico da pesquisa, com a análise de mais recursos, os quais possam dar mais consistência e formulação da fundamentação e resultados.

A pesquisa buscou entender como e a partir de quando alguns meios como mídia, literatura e artes passaram a representar o Nordeste como uma região extremamente pobre, seca e miserável e identificamos a gênese desses estereótipos com raízes históricas no período imperial (GUERRA, 1981).

Para este fim, a metodologia da análise semiótica e bibliográfica foi empregada com ênfase em alguns recursos que constituem meios de propagação e/ou difusão dessas construções, tais como: imagens em livros didáticos, poemas, letras de músicas, obras literárias, científicas e produções televisivas. A base teórica utilizada foi respaldada pelas obras de autores que abordam a temática das representações sociais e construções sociais (Michel de Certeau) e especificamente quando se fala em Nordeste, recorreu-se às obras referenciadas em Durval Muniz de Albuquerque Jr e Renato Ortiz.

A pesquisa garimpou produções clássicas, de pequenas e grandes circulações, que têm em comum as convenções sobre o Nordeste, fundadas em períodos em que a região passou por grandes mazelas e catástrofes naturais, como as secas de 1870 a 1877, que ficaram conhecidas como "Anos malditos". Período esse em que mais de 118.900 pessoas morreram de fome. Contudo, por mais que as décadas tenham passado, permaneceu certo convencimento de que o Nordeste é somente o lugar da seca, do sofrimento, da pobreza extrema etc. Se o Nordeste traz múltiplas expressões e possui práticas culturais específicas e singularidades próprias de um território caracterizado por sequelas impostas pela natureza e pelas ações (des)humanas, contudo, ele é o território de referências, identidades, atributos culturais que devem ser redescobertos em sua naturalidade, sem preconceitos e estereótipos.

Necessário é, portanto, ampliar os repertórios do entendimento e percepção que se tem do Nordeste e sua gente, para, posteriormente utilizá-los no ofício do Ensino. Fundamental é fazer uso das novas linguagens, das novas ferramentas de comunicação e de convencimento para se poder reorganizar os símbolos e superar a visão hegemônica 
que, na maior parte das vezes, é injusta e parcial. A História e o Ensino de História, através de seus métodos críticos auxiliam então, alunos e professores a reconhecerem e valorizarem os aspectos diferenciados de uma mesma brasilidade.

\section{Referências}

ALBUQUERQUE Jr., Durval Muniz de. A Invenção do Nordeste e outras artes. São Paulo: Cortez. 2001.

BEZERRA, Holien Gonçalves. Ensino de História: Conteúdos e conceitos básicos. In: KARNAL, Leandro (Org.). História na sala de aula: conceitos, práticas e propostas. 6. ed. São Paulo: Contexto, 2010.

BITTENCOURT, Circe. Livros didáticos entre textos e imagens. In: BITTENCOURT, Circe M. F. (Org.). O saber histórico na sala de aula. 12. ed. São Paulo: Contexto, 2015.

BLOCH, Marc. Apologia da história ou o ofício de historiador. Rio de Janeiro: Zahar, 2001. CERTEAU, Michel de. A escrita da história. 2. ed. Rio de Janeiro: Forense universitária, 2008.

CERTEAU. Michel. A cultura no plural. Campinas: Papirus, 1995.

CERTEAU. Michel. A invenção do cotidiano 2: morar, cozinhar. 5. ed. Petrópolis: Vozes. 1996.

CERTEAU. Michel. A invenção do cotidiano 1: artes de fazer. Petrópolis: Vozes. 1994.

CHIZZOTI, Antônio. Pesquisa em ciências humanas e sociais. 3. ed. São Paulo: Cortez, 1992.

CUNHA, Euclides da. Os sertões. São Paulo: Cultrix-MEC, 1973.

GUERRA, Paulo Brito. A civilização da Seca. Rio de Janeiro: Civilização Brasileira, 1981. 
HOLANDA, Aurélio Buarque de. Dicionário de Língua Portuguesa. Curitiba: Editora Positivo, 2012.

LUIZ, Wadeck. A morte certeira no sertão nordestino. Joinville: Clube dos Autores Publicações, 2003.

NADAI, Elza. O ensino de História no Brasil: trajetória e perspectiva. Revista Brasileira de História, São Paulo. v. 13, n. 25-26, p. 143-162, set. 1992/ago. 1993.

PAIVA, Eduardo França. História e imagens. 2. ed. Belo Horizonte: Autêntica, 2006. PESAVENTO, Sandra Jatahy. História \& história cultural. Belo Horizonte: Autêntica, 2003. WARNIER, Jean-Pierre. A mundialização da cultura. São Paulo: Edusc, 2000.

RAMOS, Hélio. Nordeste: Nação espoliada. Rio de Janeiro: Civilização Brasileira, 1987. 